\author{
JURNAL EINSTEIN \\ Jurnal Hasil Penelitian Bindang Fisika \\ Available online http://jurnal.unimed.ac.id/2012/index.php/einsten \\ e-issn: $2407-747 x$, p-issn $2338-1981$
}

\title{
IDENTIFIKASI KEJERNIHAN AIR SUMUR BOR DITINJAU DARI DAYA HANTAR LISTRIK (DHL) DENGAN KONDUKTIVITIMETER DI DESA SENTANG KECAMATAN TELUK MENGKUDU KABUPATEN SERDANG BEDAGAI
}

\section{Dewi Feronika Manullang dan Nurdin Siregar}

\author{
Jurusan Fisika, Fakultas Matematika dan Ilmu Pengetahuan Alam, Universitas Negeri Medan, \\ Indonesia \\ dewimanullang93@gmail.com
}

Diterima April 2018; Disetujui Mei 2018; Dipublikasikan Juni 2018

\begin{abstract}
ABSTRAK
Penelitian ini bertujuan untuk mengetahui kejernihan air, daya hantar listrik, salinitas, $\mathrm{pH}$, suhu dan kandungan logam pada air sumur bor di Kecamatan Teluk Mengkudu pada empat dusu di Desa Sentang Kec. Teluk Mengkudu dengan titik acuan 030 57'593 LU dan 990 12 ' 545 BT. Pengambilan sampel dilakukan dengan mengambil sampel air laut dimulai dari titik acuan (garis pantai) hingga air laut murni dan mengambil sampel air sumur bor dimulai dari sumur bor terdekat dengan titik acuan (garis pantai), mengukur suhu dan daya hantar listrik kedua sampel serta kedalaman dan jarak sumur bor dari titik acuan (garis pantai). Data pengukuran daya hantar listrik yang diperoleh dikonversikan pada suhu $25^{\circ} \mathrm{C}$. Semua air sumur bor dari 20 sampel telah terintrusi tinggi yaitu mencapai $25 \%$ dan terintrusi agak tinggi yaitu mencapai $75 \%$. Daya Hantar Listrik (DHL) air sumur bor di Desa Sentang 390,62 - 556,69 $\mu \mathrm{mho} / \mathrm{cm}, 2^{\circ} \mathrm{C}$, salinitas 213- 296 $\mathrm{mg} / \mathrm{L}$, suhu 26,9-27,6 $\mathrm{C}$. Untuk analisa pengujian sampel air sumur bor yang memiliki nilai DHL tertinggi $556,69 \mu \mathrm{mho} / \mathrm{cm}, 25^{\circ} \mathrm{C}$ terdapat logam besi (Fe) sebesar $0,36 \mathrm{mg} /$ l,sedangkan untuk sampel air sumur bor yang memiliki DHL terendah $390,62 \mu \mathrm{mho} / \mathrm{cm}, 25^{\circ} \mathrm{C}$ terdapat kandungan logam besi (Fe) sebesar $1,83 \mathrm{mg} / \mathrm{l}$.
\end{abstract}

Kata Kunci : Kejernihan Air, Intrusi Air Laut, DHL, Konduktivitimeter.

\section{PENDAHULUAN}

Air merupakan faktor yang sangat penting dalam kehidupan manusia, karena zat pembentuk tubuh manusia sebagian besar adalah air, bahkan hampir 60 - $70 \%$ tubuh manusia mengandung air. Setiap hari manusia mengkonsumsi air bersih untuk keperluan minum minimal sebanyak 2 liter per hari. Sumber utama air yang ada dipermukaan dan bawah permukaaan tanah berasal dari hujan. Hujan yang turun ke bumi sebagian akan mengalir sebagai air permukaan dan sebagian lagi meresap ke dalam tanah, kemudian membentuk air tanah. Baik air permukaan maupun air tanah mengalir dari daerah yang lebih tinggi yaitu dari daerah resapan atau daerah imbuhan menuju daerah yang lebih rendah dan akhirnya menuju ke laut. Berdasarkan Peraturan Pemerintah Republik Indonesia Nomor 82 Tahun 2001, menyatakan bahwa yang dimaksud dengan air adalah semua air yang terdapat di atas dan di bawah permukaan tanah kecuali air laut dan air fosil. Air yang berada di atas lapisan tanah (dalam bentuk cair) dinamakan air permukaan dan air 
yang berada di bawah lapisan tanah dinamakan air tanah (Gusnisar,2012).

Air tanah merupakan salah satu komponen penting dari sumber daya air yang baik untuk air bersih dan air minum, dibandingkan dengan sumber air lainnya. Keberadaan air tanah yang hampir dapat ditemui di setiap lahan tanah menyebabkan sumber daya ini menjadi andalan utama terutama untuk kebutuhan domestik sehari-hari, industri, irigasi, jasa, penyediaan air perkotaan, dan sebagainya. Oleh karena itu, air tanah masih menjadi andalan bagi masyarakat untuk digunakan sebagai sumber pasokan air bersih baik untuk memenuhi keperluan rumah tangga maupun untuk menunjang usaha komersial. Pengambilan air tanah yang berlebihan akan menimbulkan permasalahan baru dalam mengakses air bersih yaitu penurunan muka air tanah. Sehingga kemungkinan air menyusup kedalam sumur. Permasalahan lain yang akan timbul ialah intrusi air laut pada bagian pesisir. Intrusi air laut menyebabkan air tanah yang berada dibagian pesisir akan terasa payau (Hermaningsih,2007).

Di daerah pesisir pantai, penggunaan air tanah oleh penduduk perlu mendapat perhatian yang serius karena masih terbatasnya sarana Perusahaan Daerah Air Minum (PDAM), seiring dengan semakin meningkatnya laju pertumbuhan penduduk, maka tingkat konsumsi air juga semakin tinggi. Pentingnya air bawah tanah karena potensinya yang diperkirakan $98 \%$ dari air tawar yang ada di permukaan bumi, sedangkan selebihnya berada di danau, sungai dan lain-lain (Hendrayana, 2002).

Evaluasi terhadap permasalahan terjadinya intrusi air laut di wilayah pesisir desa Sentang kecamatan Teluk Mengkudu sangat penting dilakukan dalam upaya pengelolaan sumber daya air tanah, hal ini agar kuantitas dan kualitas pasokan air tanah dalam jangka panjang tetap terpenuhi. Informasi seperti ini diperlukan, karena bertambahnya penduduk dan kegiatannya pada masa yang akan datang semakin meningkat, sehingga pemanfaatan air tanah pada sumur bor juga semakin meningkat (Suhartono,2013).

\section{METODE PENLITIAN}

\subsection{Peralatan Yang Digunakan}

Penelitian ini akan dilakukan di Desa Sentang Kecamatan Serdang Bedagai dan di Laboratorium fisika Universitas Negeri Medan untuk pengukuran daya hantar listrik, $\mathrm{pH}$, salinitas dan suhu dan penelitian kadar logam beratnya akan dilaksanakan di Laboratorium Pengujian Balai Riset Dan Standardisasi Industri Medan Medan dan waktu penelitian direncanakan dimulai pada bulan Desember 2014 sampai dengan Maret 2015.

Alat yang digunakan dalam penelitian ini adalah GPS (Global Position System), Gelas beaker, Meteran, Konduktivitimeter, Termometer digital. Bahan yang digunakan dalam penelitian ini terdiri dari Air Sumur Bor, Air Laut, Aquabides, Data Geologi (Peta Geologi).

\subsection{Pengolahan Data}

\section{Analisa Model Regresi Linear Berganda}

Penelitian ini dilakukan dengan metode survey dan mengukur DHL (Daya Hantar Listrik) air tanah (sumur bor), Pengujian ini dilakukan dengan model analisa model regresi berganda dengan persamaan :

$$
\hat{Y}=a_{0}+a_{1} X_{1}+a_{2} X_{2}+. .+a_{k} X_{k}
$$

Di dalam penelitian ini variabel terikat adalah $\hat{Y}$ (Daya hantar listrik), dan variabelvariabel bebas adalah kedalaman sumur bor $\left(X_{1}\right)$ dan jarak sumur bor dari garis pantai $\left(X_{2}\right)$, maka bentuk persamaan regresinya :

$$
\hat{Y}=a_{0}+a_{1} X_{1}+a_{2} X_{2}
$$

Koefisien-koefisien $a_{0}, a_{1}, a_{2}$ ditentukan dengan menggunakan metode kuadrat terkecil dengan persamaan :

$$
\begin{aligned}
& \Sigma Y_{i}=a_{0} n+a_{1} \Sigma X_{1 i}+a_{2} \Sigma X_{2 i} \\
& \Sigma Y_{i} X_{1 i}=a_{0} \Sigma X_{1 i}+a_{1} \Sigma X_{1 i}^{2}+a_{2} \Sigma X_{1 i} X_{2 i} \\
& \Sigma Y_{i} X_{2 i}=a_{0} \Sigma X_{2 i}+a_{1} \Sigma X_{1 i} X_{2 i}+a_{2} \Sigma X^{2}{ }_{2 i}
\end{aligned}
$$

Untuk menguji linieritas persamaan (3.1) digunakan uji $\mathrm{F}$ dengan persamaan :

$$
\begin{aligned}
& F=\frac{J K_{r e g} / k}{J K_{r e s} /(n-k-1)} \\
& \text { Jika } X_{1}=X_{1 i}-\bar{X}_{1}, X_{2}=X_{2 i}-\bar{X}_{2}, \ldots, \\
& X_{k}=X_{k i}-\bar{X}_{k} \text { dan } y_{i}=Y_{i}-\bar{Y} \text { maka jumlah } \\
& \text { kuadrat-kuadrat regresi dapat dihitung dengan } \\
& \text { persamaan: }
\end{aligned}
$$


$J K_{r e g}=a_{1} \Sigma X_{1 i} y_{i}+a_{2} \Sigma X_{2 i} y_{i}+\ldots \ldots \ldots+a_{k} \Sigma X_{k i} y_{i}$ (5)

Jumlah kuadrat-kuadrat residu dapat dihitung dengan persamaan :

$J K_{r e s}=\Sigma\left(Y_{i}-\hat{Y}_{i}\right)^{2}$

\section{Analisa Air Laut dan Air Sumur}

Pada pengolahan data nilai DHL pada sample dilakukan pada suhu yang sama yaitu $25^{\circ}$

C. Untuk mendapatkan nilai DHL pada suhu $25^{\circ}$

C maka dilakukan interpolasi linier dengan menggunakan persamaan :

$D H L\left(\mu\right.$ mhos $\left./ \mathrm{cm}, 25^{\circ} C\right)=\frac{25}{t_{\text {air }}} D H L_{p}$

Berdasarkan nilai ppm dan DHL pada suhu tertentu yang dilakukan dilaboratorium dapat dihitung DHL pada suhu $25^{\circ} \mathrm{C}$ dengan persamaan:

$D H L_{25}=\frac{D H L_{t}(p p m)}{1+0,0191(t-25)}$

\section{HASIL DAN PEMBAHASAN}

\subsection{Hasil Penelitian}

\subsubsection{Air Laut}

Tabel 1. Daya Hantar Listrik (DHL) Air Laut sebagai Fungsi jarak

\begin{tabular}{|c|c|c|c|c|c|c|}
\hline $\begin{array}{c}\text { No } \\
\cdot\end{array}$ & $\begin{array}{c}\text { Kode } \\
\text { Samp } \\
\mathrm{el}\end{array}$ & $\begin{array}{c}\text { Jara } \\
\mathrm{k}\end{array}$ & $\begin{array}{c}\text { DHL } \\
(\mu \mathrm{mho} / \\
\mathrm{cm})\end{array}$ & $\begin{array}{c}\text { Suh } \\
\mathrm{u} \\
\left({ }^{\circ} \mathrm{C}\right)\end{array}$ & $\begin{array}{c}\mathrm{pH} \\
(\mathrm{mg} / \\
\mathrm{L})\end{array}$ & $\begin{array}{c}\text { Salini } \\
\text { tas } \\
(\mathrm{mg} / \mathrm{L} \\
)\end{array}$ \\
\hline 1 & $\begin{array}{c}\text { Titik } \\
\text { Acua } \\
\mathrm{n}\end{array}$ & 25 & 19900 & $\begin{array}{c}25, \\
9\end{array}$ & 7,2 & 10,1 \\
\hline 2 & AL 1 & 125 & 20400 & $\begin{array}{c}25, \\
9\end{array}$ & 8,1 & 10,6 \\
\hline 3 & AL 2 & 625 & 20900 & $\begin{array}{c}25, \\
9\end{array}$ & 8,0 & 10,4 \\
\hline 4 & AL 3 & $\begin{array}{c}162 \\
5\end{array}$ & 21100 & $\begin{array}{c}25, \\
9\end{array}$ & 8,4 & 10,8 \\
\hline 5 & AL 4 & $\begin{array}{c}362 \\
5\end{array}$ & 21400 & $\begin{array}{c}26, \\
9\end{array}$ & 8,1 & 10,5 \\
\hline
\end{tabular}

\section{Hubungan DHL Air Laut Terhadap Jarak}



Gambar 1. Grafik regresi linear antara jarak sampel air laut dari garis pantai $(\mathrm{m})$ terhadap DHL air laut $\left(\mu \mathrm{mho} / \mathrm{cm}, 25^{\circ} \mathrm{C}\right)$

\subsubsection{Air Sumur Bor}

Sampel air sumur bor diambil dari sumur bor yang terdekat dari titik acuan sampai ke pemukiman penduduk. Data hasil pengukuran sampel air sumur bor dapat dilihat pada gambar 2.

Tabel 2. Data Hasil Pengukuran Daya Hantar Listrik (DHL) Air Laut Pada Suhu $25^{\circ} \mathrm{C}$

\begin{tabular}{|c|c|c|c|c|c|c|c|}
\hline $\begin{array}{l}\mathrm{N} \\
\mathrm{o}\end{array}$ & $\begin{array}{c}\text { Jar } \\
\text { ak } \\
(\mathrm{m} \\
)\end{array}$ & $\begin{array}{l}\text { Keda } \\
\text { lama } \\
n(m)\end{array}$ & $\begin{array}{c}\text { DHL } \\
(\mu m h \\
o / c m \\
)\end{array}$ & $\begin{array}{l}\mathrm{Su} \\
\mathrm{hu} \\
(\mathrm{o} \\
\mathrm{C})\end{array}$ & $\begin{array}{c}\mathrm{pH} \\
( \\
\mathrm{mg} / \\
\mathrm{L})\end{array}$ & $\begin{array}{c}\text { Sali } \\
\text { nita } \\
\mathrm{s} \\
(\mathrm{mg} / \\
\mathrm{L})\end{array}$ & $\begin{array}{l}\mathrm{DHL} \\
(\mu \mathrm{mh} \\
o / \mathrm{cm}, \\
\left.25^{\circ} \mathrm{C}\right)\end{array}$ \\
\hline 1 & $\begin{array}{l}22 \\
27 \\
\end{array}$ & 120 & 553 & $\begin{array}{c}26 \\
, 9 \\
\end{array}$ & 7,8 & 278 & $\begin{array}{c}513,9 \\
4\end{array}$ \\
\hline 2 & $\begin{array}{l}23 \\
88 \\
\end{array}$ & 114 & 599 & $\begin{array}{r}26 \\
, 9 \\
\end{array}$ & 7,7 & 297 & $\begin{array}{c}556,6 \\
9 \\
\end{array}$ \\
\hline 3 & $\begin{array}{l}24 \\
00\end{array}$ & 120 & 592 & $\begin{array}{r}27 \\
, 2\end{array}$ & 7,2 & 296 & $\begin{array}{c}544,1 \\
1\end{array}$ \\
\hline 4 & $\begin{array}{l}25 \\
41 \\
\end{array}$ & 120 & 574 & $\begin{array}{r}27 \\
, 2 \\
\end{array}$ & 7,3 & 285 & $\begin{array}{c}527,5 \\
7 \\
\end{array}$ \\
\hline 5 & $\begin{array}{l}25 \\
60 \\
\end{array}$ & 90 & 425 & $\begin{array}{r}27 \\
, 2 \\
\end{array}$ & 7,4 & 213 & $\begin{array}{c}390,6 \\
2 \\
\end{array}$ \\
\hline 6 & $\begin{array}{l}26 \\
38 \\
\end{array}$ & 114 & 567 & $\begin{array}{r}27 \\
, 6 \\
\end{array}$ & 7,0 & 282 & $\begin{array}{c}513,5 \\
8 \\
\end{array}$ \\
\hline 7 & $\begin{array}{l}27 \\
71 \\
\end{array}$ & 114 & 555 & $\begin{array}{r}27 \\
, 6 \\
\end{array}$ & 7,1 & 278 & $\begin{array}{c}502,7 \\
1 \\
\end{array}$ \\
\hline 8 & $\begin{array}{l}27 \\
74 \\
\end{array}$ & 102 & 537 & $\begin{array}{r}27 \\
, 6 \\
\end{array}$ & 7,4 & 269 & $\begin{array}{c}486,4 \\
1\end{array}$ \\
\hline
\end{tabular}




\begin{tabular}{|r|r|c|r|r|c|c|c|}
\hline 9 & 28 & 96 & 559 & 27 & 7,4 & 279 & 506,3 \\
& 25 & & &, 6 & & & 4 \\
\hline 1 & 28 & 108 & 535 & 27 & 7,7 & 267 & 488,1 \\
0 & 54 & & &, 4 & & & 3 \\
\hline 1 & 32 & 108 & 560 & 27 & 6,9 & 279 & 507,2 \\
1 & 37 & & &, 6 & & & 4 \\
\hline 1 & 34 & 102 & 580 & 27 & 7,4 & 288 & 525,3 \\
2 & 46 & & &, 6 & & & 6 \\
\hline 1 & 36 & 96 & 565 & 27 & 7,8 & 284 & 511,7 \\
3 & 87 & & &, 6 & & & 7 \\
\hline 1 & 37 & 120 & 582 & 27 & 7,9 & 291 & 527,1 \\
4 & 82 & & &, 6 & & & 7 \\
\hline 1 & 38 & 120 & 556 & 27 & 8,1 & 278 & 503,6 \\
5 & 06 & & &, 6 & & & 2 \\
\hline 1 & 38 & 108 & 561 & 27 & 8,3 & 280 & 515,6 \\
6 & 13 & & &, 2 & & & 2 \\
\hline 1 & 48 & 120 & 555 & 27 & 8,4 & 278 & 510,1 \\
7 & 71 & & &, 2 & & & 1 \\
\hline 1 & 48 & 108 & 581 & 27 & 8,3 & 289 & 534,0 \\
8 & 82 & & &, 2 & & & 1 \\
\hline 1 & 50 & 108 & 584 & 27 & 8,2 & 292 & 536,7 \\
9 & 58 & & &, 2 & & & 6 \\
\hline 2 & 60 & 120 & 569 & 27 & 8,1 & 284 & 522,9 \\
0 & 70 & & &, 2 & & & 7 \\
\hline
\end{tabular}

\begin{tabular}{|c|c|c|c|c|c|}
\hline 2 & SB 2 & $\begin{array}{l}23 \\
88\end{array}$ & 114 & 556,69 & $\begin{array}{c}\text { Terintrusi } \\
\text { Tinggi }\end{array}$ \\
\hline 3 & SB 3 & $\begin{array}{l}24 \\
00\end{array}$ & 120 & 544,11 & $\begin{array}{c}\text { Terintrusi } \\
\text { Tinggi }\end{array}$ \\
\hline 4 & SB 4 & $\begin{array}{l}25 \\
41\end{array}$ & 120 & 527,57 & $\begin{array}{c}\text { Terintrusi } \\
\text { agak Tinggi }\end{array}$ \\
\hline 5 & SB 5 & $\begin{array}{l}25 \\
60\end{array}$ & 90 & 390,62 & $\begin{array}{l}\text { Terintrusi } \\
\text { agak Tinggi }\end{array}$ \\
\hline 6 & SB 6 & $\begin{array}{l}26 \\
38 \\
\end{array}$ & 114 & 513,58 & $\begin{array}{c}\text { Terintrusi } \\
\text { agak Tinggi }\end{array}$ \\
\hline 7 & SB 7 & $\begin{array}{l}27 \\
71\end{array}$ & 114 & 502,71 & $\begin{array}{c}\text { Terintrusi } \\
\text { agak Tinggi }\end{array}$ \\
\hline 8 & SB 8 & $\begin{array}{l}27 \\
74\end{array}$ & 102 & 486,41 & $\begin{array}{l}\text { Terintrusi } \\
\text { agak Tinggi }\end{array}$ \\
\hline 9 & SB 9 & $\begin{array}{l}28 \\
25 \\
\end{array}$ & 96 & 506,34 & $\begin{array}{c}\text { Terintrusi } \\
\text { agak Tinggi }\end{array}$ \\
\hline 1 & SB 10 & $\begin{array}{l}28 \\
54\end{array}$ & 108 & 488,13 & $\begin{array}{c}\text { Terintrusi } \\
\text { agak Tinggi }\end{array}$ \\
\hline $\begin{array}{l}1 \\
1\end{array}$ & SB 11 & $\begin{array}{l}32 \\
37\end{array}$ & 108 & 507,24 & $\begin{array}{c}\text { Terintrusi } \\
\text { agak Tinggi }\end{array}$ \\
\hline 1 & SB 12 & $\begin{array}{l}34 \\
46\end{array}$ & 102 & 525,36 & $\begin{array}{l}\text { Terintrusi } \\
\text { agak Tinggi }\end{array}$ \\
\hline $\begin{array}{l}1 \\
3\end{array}$ & SB 13 & $\begin{array}{l}36 \\
87\end{array}$ & 96 & 511,77 & $\begin{array}{c}\text { Terintrusi } \\
\text { agak Tinggi }\end{array}$ \\
\hline $\begin{array}{l}1 \\
4 \\
\end{array}$ & SB 14 & $\begin{array}{l}37 \\
82 \\
\end{array}$ & 120 & 527,17 & $\begin{array}{c}\text { Terintrusi } \\
\text { agak Tinggi }\end{array}$ \\
\hline 1 & SB 15 & $\begin{array}{l}38 \\
06\end{array}$ & 120 & 503,62 & $\begin{array}{c}\text { Terintrusi } \\
\text { agak Tinggi }\end{array}$ \\
\hline 1 & SB 16 & $\begin{array}{l}38 \\
13 \\
\end{array}$ & 108 & 515,62 & $\begin{array}{c}\text { Terintrusi } \\
\text { agak Tinggi }\end{array}$ \\
\hline 1 & SB 17 & $\begin{array}{l}48 \\
71 \\
\end{array}$ & 120 & 510,11 & $\begin{array}{c}\text { Terintrusi } \\
\text { agak Tinggi }\end{array}$ \\
\hline 1 & SB 18 & $\begin{array}{l}48 \\
82 \\
\end{array}$ & 108 & 534,01 & $\begin{array}{c}\text { Terintrusi } \\
\text { agak Tinggi }\end{array}$ \\
\hline 1 & SB 19 & $\begin{array}{l}50 \\
58 \\
\end{array}$ & 108 & 536,76 & $\begin{array}{c}\text { Terintrusi } \\
\text { Tinggi }\end{array}$ \\
\hline $\begin{array}{l}2 \\
0\end{array}$ & SB 20 & $\begin{array}{l}60 \\
70 \\
\end{array}$ & 120 & 522,97 & $\begin{array}{c}\text { Terintrusi } \\
\text { agak Tinggi }\end{array}$ \\
\hline
\end{tabular}

Gambar 2. Kontur Daya Hantar Listrik (DHL)

Air Sumur Bor $\left(\mu \mathrm{mho} / \mathrm{cm}, 25^{\circ} \mathrm{C}\right)$ Terhadap Jarak (m) dan Kedalaman (m)

Tabel 3. Klasifikasi Intrusi Air Laut Pada Sumur Bor Berdasarkan Daya Hantar Listrik (DHL)

\begin{tabular}{|c|c|c|c|c|c|}
\hline $\mathrm{N}$ & Kode & Jar & Kedal & DHL & Klasifikasi \\
o & $\begin{array}{c}\text { Sampe } \\
\text { l }\end{array}$ & $\begin{array}{c}\text { ak } \\
(\mathrm{m}\end{array}$ & $\begin{array}{c}\text { aman } \\
(\mathrm{m})\end{array}$ & $\begin{array}{c}(\mu \mathrm{mho} / \mathrm{c} \\
\left.\mathrm{m}, 25^{\circ} \mathrm{C}\right)\end{array}$ & $\begin{array}{c}\text { Intrusi } \\
\end{array}$ \\
\hline 1 & SB 1 & 22 & 120 & 513,94 & $\begin{array}{c}\text { Terintrusi } \\
\text { agak Tinggi }\end{array}$ \\
\hline
\end{tabular}

\subsubsection{Hubungan Jarak Dan Kedalaman Terhadap Daya Hantar Listrik (DHL) Air Sumur Bor Melalui Analisis Regresi Linear Berganda}

Untuk menganalisa pengaruh jarak sumur bor dari garis pantai dan kedalaman sumur bor secara bersama-sama terhadap daya hantar listrik (DHL) dilakukan analisa regresi linear berganda .

Harga-harga yang diperlukan untuk menentukan persamaan regresi linear berganda, 
uji statistik $F$ dan perhitungan koefisienkoefisien korelasi. Berdasarkan hasil perhitungan diperoleh :

$$
\begin{aligned}
& \sum X_{1}=2208 \\
& \sum X_{2}=68630 \\
& \sum Y=10226,54 \\
& \sum X_{1} Y=1132357,26 \\
& \sum X_{2} Y=35244627 \\
& \sum X_{1} X_{2}=7605642 \\
& \bar{X}_{1}=110.4 \overline{X_{2}}=3431.5 \bar{Y}=511.327 \\
& \sum X_{1}{ }^{2}=245448 \\
& \sum X_{2}{ }^{2}=257154868 \\
& \sum Y^{2}=5250188.474 \\
& a_{0}=-983,94 a_{1}=0,303 a_{2}=0,426
\end{aligned}
$$

Berdasarkan hasil perhitungan diperoleh persamaan regresi linear berganda yaitu :

$\hat{Y}=-983,94+0,303 x_{1}+0,426 x_{2}$

Dengan

$$
\begin{aligned}
& x_{1}=\text { Kedalaman } \\
& x_{2}=\text { Jarak }
\end{aligned}
$$

Untuk menguji apakah persamaan itu nyata atau tidak nyata , digunakan uji statistik F berdasarkan persamaan (3.4). Dari hasil analisa stasistik diperoleh $\quad J K_{\text {reg }}=14853627$ dan $J K_{\text {res }}=12002237 \quad$ sehingga diperoleh $F_{h}=0.0363992$ Dari daftar distribusi F dengan $\mathrm{dk}$ pembilang $=2$, dk penyebut $=17 \mathrm{dan} \alpha=0.05$ sehingga diperoleh $R^{2}=2,979$ atau $R=1,489$.

\subsubsection{Kandungan Logam Pada Air Sumur Bor Kandungan Logam Pada Air Sumur Bor 2}

Kandungan logam pada air sumur bor melalui pengujian sampel air sumur bor $2 \mathrm{di}$ Laboratorium Kimia Balai Riset Dan Standarisasi Industri Medan dapat dilihat pada tabel

Tabel 4. Data Hasil Pengujian sampel air sumur bor 2

\begin{tabular}{|c|c|c|c|c|}
\hline $\begin{array}{c}\mathrm{N} \\
\mathrm{o}\end{array}$ & $\begin{array}{c}\text { Paramete } \\
\text { r Logam }\end{array}$ & $\begin{array}{c}\text { Satua } \\
\mathrm{n}\end{array}$ & $\begin{array}{c}\text { Baha } \\
\mathrm{n} \\
\text { Baku }\end{array}$ & $\begin{array}{c}\text { Hasil } \\
\text { Analis } \\
\mathrm{a}\end{array}$ \\
\hline 1 & Besi & $\mathrm{mg} / \mathrm{L}$ & 1 & 0,36 \\
\hline 2 & Kadmium & $\mathrm{mg} / \mathrm{L}$ & 0.005 & $<0,006$ \\
\hline
\end{tabular}

\begin{tabular}{|c|c|c|c|c|}
\hline 3 & Timbal & $\mathrm{mg} / \mathrm{L}$ & 0.05 & 0,04 \\
\hline 4 & Tembaga & $\mathrm{mg} / \mathrm{L}$ & 4,00 & $<0,01$ \\
\hline
\end{tabular}

\section{Kandungan Logam Pada Air Sumur Bor 5}

Kandungan logam pada air sumur bor melalui pengujian sampel air sumur bor 5 di Laboratorium Kimia Balai Riset Dan Standarisasi Industri Medan dapat dilihat pada tabel

Tabel 4. Data Hasil Pengujian sampel air sumur bor 2

\begin{tabular}{|c|c|c|c|c|}
\hline No & $\begin{array}{c}\text { Parameter } \\
\text { Logam }\end{array}$ & Satuan & $\begin{array}{c}\text { Bahan } \\
\text { Baku }\end{array}$ & $\begin{array}{c}\text { Hasil } \\
\text { Analisa }\end{array}$ \\
\hline 1 & Besi & $\mathrm{mg} / \mathrm{L}$ & 1 & 0,36 \\
\hline 2 & Kadmium & $\mathrm{mg} / \mathrm{L}$ & 0.005 & $<0,006$ \\
\hline 3 & Timbal & $\mathrm{mg} / \mathrm{L}$ & 0.05 & 0,04 \\
\hline 4 & Tembaga & $\mathrm{mg} / \mathrm{L}$ & 4,00 & $<0,01$ \\
\hline
\end{tabular}

\section{Kandungan Logam Pada Air Sumur Bor 5}

Kandungan logam pada air sumur bor melalui pengujian sampel air sumur bor 5 di Laboratorium Kimia Balai Riset Dan Standarisasi Industri Medan dapat dilihat pada tabel

\begin{tabular}{|c|c|c|c|c|}
\hline $\begin{array}{c}\text { N } \\
\text { o }\end{array}$ & $\begin{array}{c}\text { Paramete } \\
\text { r Logam }\end{array}$ & $\begin{array}{c}\text { Satua } \\
\mathrm{n}\end{array}$ & $\begin{array}{c}\text { Baha } \\
\mathrm{n} \\
\text { Baku }\end{array}$ & $\begin{array}{c}\text { Hasil } \\
\text { Analis } \\
\mathrm{a}\end{array}$ \\
\hline 1 & Besi & $\mathrm{mg} / \mathrm{L}$ & 1 & 1,83 \\
\hline 2 & Kadmium & $\mathrm{mg} / \mathrm{L}$ & 0.005 & $<0,006$ \\
\hline 3 & Timbal & $\mathrm{mg} / \mathrm{L}$ & 0.05 & $<0,02$ \\
\hline 4 & Tembaga & $\mathrm{mg} / \mathrm{L}$ & 4,00 & $<0,01$ \\
\hline
\end{tabular}

\subsection{Pembahasan \\ Air Laut}

Dari gambar grafik 3.1 dapat dilihat bahwa semakin jauh dari garis pantai, DHL air laut akan semakin tinggi. Dan berdasarkan nilai koefisien determinasi dari grafik diperoleh hubungan yang signifikan antara DHL air laut terhadap jarak, dengan nilai $\mathrm{R}=0,997$ atau sekitar 99,7\% pengaruh jarak terhadap nilai DHL air laut.

\section{Air Sumur Bor}

Dari hasil pengukuran sumur bor bahwa jarak dan kedalaman sumur dikatakan secara bersama - sama berpengaruh sangat kecil terhadap Daya Hantar Listrik (DHL) air sumur bor atau dapat dikatakan bahwa regresi linear berganda bersifat tidak nyata. Apabila ditinjau dari faktor lain yang terdiri dari faktor geologi, daerah kecamatan Teluk Mengkudu memiliki struktur tanah yang terdiri dari kerikil, pasir, 
lempung dan rawa gambut yang sangat mendominasi di setiap tempat, hal ini merupakan salah satu faktor terbesar yang menyebabkan air di daerah Teluk Mengkudu memiliki DHL yang tinggi, yang rata - rata air sumur warga telah terintrusi dengan tingkatan yang berbeda - beda.

\section{Kandungan Logam Air Sumur}

Berdasarkan hasil pengujian sampel air sumur bor yang memiliki nilai DHL tertinggi $\left(556,69 \mu \mathrm{mho} / \mathrm{cm}^{2} 25^{\circ} \mathrm{C}\right)$ terdapat logam Besi (Fe) sebesar 0,36 mg/l, sedangkan untuk sampel air sumur bor yang memiliki nilai DHL terendah (390,62 $\left.\mu \mathrm{mho} / \mathrm{cm}, 25^{\circ} \mathrm{C}\right)$ terdapat kandungan logam Besi (Fe) sebesar 1,83 mg/l. Berdasarkan permenkes 416/1990 dapat dilihat pada Tabel 2.6. Persyaratan Kualitas Air Minum bahwa air sumur bor dengan DHL terendah telah melewati batas baku mutu kualitas air bersih. Sedangkan untuk unsur Kadmium (Cd) terkandung <0,006 $\mathrm{mg} / \mathrm{l}$ sedangkan baku mutu kandungan $\mathrm{Cd}$ adalah 0,05 mg/l hal ini berarti bahwa kandungan logam Cd pada sumur bor 2 tidak melewati batas baku mutu kualitas air bersih. Untuk kandungan Timbal $(\mathrm{Pb})$ terkandung $0,04 \mathrm{mg} / \mathrm{l}$ sedangkan baku mutu kandungan $\mathrm{Pb}$ adalah 0,05 mg/l hal ini berarti bahwa kandungan logam $\mathrm{Pb}$ pada sumur bor 2 tidak melewati batas baku mutu kualitas air bersih. Untuk kandungan Tembaga pada air sumur bor 2 adalah $<0,01 \mathrm{mg} / 1$.

Untuk analisa unsur Kadmium (Cd) terkandung $<0,006 \mathrm{mg} / \mathrm{l}$ sedangkan baku mutu kandungan $\mathrm{Cd}$ adalah $0,05 \mathrm{mg} / \mathrm{l}$ hal ini berarti bahwa kandungan logam Cd pada sumur bor 5 tidak melewati batas baku mutu kualitas air bersih. Sedangkan Untuk kandungan Timbal $(\mathrm{Pb})$ terkandung $<0,02 \mathrm{mg} / \mathrm{l}$ sedangkan baku mutu kandungan $\mathrm{Pb}$ adalah $0,05 \mathrm{mg} / \mathrm{l}$ hal ini berarti bahwa kandungan logam $\mathrm{Pb}$ pada sumur bor 5 tidak melewati batas baku mutu kualitas air bersih sehingga air tersebut layak untuk digunakan. Untuk kandungan Tembaga pada air sumur bor 5 adalah $<0,01 \mathrm{mg} / \mathrm{l}$.

\section{KESIMPULAN DAN SARAN}

Dari hasil penelitian yang dilakukan dapat dibuat kesimpulan :

1. Semua air sumur Bor dari 20 sampel di Desa Sentang Kec. Teluk Mengkudu Kab. Serdang Bedagai telah terintrusi air laut sekitar 25 - 75\%. Kadar intrusi air laut tertinggi pada sumur bor SB 2 dengan kedalaman $114 \mathrm{~m}$ pada jarak $2388 \mathrm{~m}$ dari garis pantai dengan nilai DHL 556,69 $\mu \mathrm{mho} / \mathrm{cm}, 25^{\circ} \mathrm{C}$, sedangkan terendah pada SB 5 dengan kedalaman $90 \mathrm{~m}$ pada jarak $2560 \mathrm{~m}$ dari garis pantai dengan nilai DHL sebesar 390,62 $\mu \mathrm{mho} / \mathrm{cm}, 25^{\circ} \mathrm{C}$.

2. Daya Hantar Listrik (DHL) air sumur bor di desa Sentang 390,62 - 556,69 $\mu \mathrm{mho} / \mathrm{cm}, 25^{\circ} \mathrm{C}$, salinitas $213-296 \mathrm{mg} / \mathrm{L}$, $\mathrm{pH}$ 6,9 - 8,4 mg/L, suhu 26,9-27,6 ${ }^{\circ} \mathrm{C}$.

3. Kandungan logam Besi $(\mathrm{Fe})$ pada sumur bor SB 5 telah melewati batas kualitas air bersih menurut baku mutu kualitas air bersih menurut Permenkes 416/1990 dapat dilihat pada Tabel 2.6. Persyaratan Kualitas Air Minum. Yaitu 1,83 mg/l. Sedangkan baku mutu Fe adalah 1. Untuk kandungan logam lainya Timbal, Kadmium, dan Tembaga pada sumur bor 2 dan 5 tidak melewati baku mutu kualitas air bersih sehingga air masih dikatakan layak untuk dikonsum

\section{Saran}

Dari hasil penelitian yang dilakukan maka disarankan :

1. Perlu diadakan penelitian lebih lanjut untuk mengetahui faktor lain yang mempengaruhi kualitas air tanah untuk menjaga kesehatan masyarakat, serta meneliti tingkat keasaman dan klorida yang terkandung pada air tanah di pesisir pantai di Desa Sentang Kecamatan Teluk Mengkudu Kabupaten Serdang Bedagai.

2. Penginfiormasian kepada masyarakat bahwa kondisi air tanah di Desa Sentang Kecamatan Teluk Mengkudu telah mengalami intrusi air laut.

3. Kepada Dinas Kesehatan Kota Madya Medan khususnya Pemerintahan Kecamatan Teluk Mengkudu perlu melakukan pemantauan kualitas dan kuantitas air bawah tanah secara berkala untuk mengetahui kondisi air bawah tanah sehingga tidak melewati batas baku mutu kualitas air bersih.

4. Pemerintahan Kabupaten Serdang Bedagai diharapkan menghimbau untuk 
Dewi Feronika Manullang dan Nurdin Siregar, Identifikasi Kejernihan Air Sumur Bor Ditinjau Dari Daya Hantar Listrik

(Dhl) Dengan Konduktivitimeter Di Desa Sentang Kecamatan Teluk Mengkudu Kabupaten Serdang Bedagai

tidak lagi menggunakan sumur bor dengan kedalaman rata - rata $90-120$ meter karena kedalaman sekian telah mengalami intrusi air laut.

5. Kepada masyarakat setempat agar pengambilan air tanah tidak dilakukan secara berlebihan.

\section{DAFTAR PUSTAKA}

Gusnisar, M., (2012), Pengaruh Sumur Resapan Terhadap Kualitas Air Tanah Di Fakultas Teknik Universitas Indonesia, FT. UI.

Hermaningsih, T dan Satmoko, Y., (2007), Alternatif Teknologi Pengolahan Air Bersih Di Daerah Pemukiman Nelayan, Jurnal Aplikasi. Vol 3 No 1

Hendrayana, H., (2002), Intrusi Air Asin Ke Dalam Akuifer Di Daratan, Teknik Geologi UGM. Yogyakarta.

Suhartono,E.,Purwanto., dan Suripin., (2013), Kondisi Intrusi Air Laut Terhadap Air Tanah pada Akuifer Di Kota Semarang. ISBN $978-602-17001-1-2$

Sudjana, (2002), Metode Statistika, Penerbit Tarsito, Bandung. 